\title{
Characteristics of energy under-reporting in children and adolescents
}

\author{
Sandrine Lioret ${ }^{1 *}$, Mathilde Touvier ${ }^{2}$, Morgan Balin ${ }^{1}$, Inge Huybrechts ${ }^{3}$, Carine Dubuisson ${ }^{1}$, \\ Ariane Dufour ${ }^{1}$, Mélanie Bertin ${ }^{1}$, Bernard Maire ${ }^{4}$ and Lionel Lafay ${ }^{1}$ \\ ${ }^{1}$ French Food Safety Agency (Afssa)/Dietary Survey Unit - Nutritional Epidemiology (OCA - EN)/27-31 Avenue du Général \\ Leclerc, 94701 Maisons-Alfort Cedex, France \\ ${ }^{2}$ Unité de Recherche en Epidémiologie Nutritionnelle (UREN), U557 Inserm/U1125 Inra/Cnam/Paris 13, CRNH IdF, SMBH \\ Paris 13, Bobigny, France \\ ${ }^{3}$ Department of Public Health, Ghent University, Ghent, Belgium \\ ${ }^{4}$ UMR 204 Nutripass (IRD, UM1, UM2, SupAgro), Montpellier, France
}

(Received 12 July 2010 - Revised 29 November 2010 - Accepted 29 November 2010 - First published online 25 January 2011)

\section{Abstract}

Under-reporting (UR) of food intake is an issue of concern, as it may distort the relationships studied between diet and health. This topic has been scarcely addressed in children. The objective of the study was to assess the extent of UR in French children and investigate associated covariates. A total of 1455 children aged 3-17 years were taken from the nationally representative cross-sectional French étude Individuelle Nationale des Consommations Alimentaires (INCA2) dietary survey (2006-7). Food intake was reported in a $7 \mathrm{~d}$ diet record. Socio-economic status, sedentary behaviour, weight perception variables and food habits were collected by questionnaires. Weight and height were measured. Under-reporters were identified according to the Goldberg criterion adapted to children. Multivariate logistic regressions investigated the associations between UR and covariates. Rates of under-reporters were 4.9 and $26.0 \%$ in children aged 3-10 and 11-17 years, respectively ( $P<0 \cdot 0001)$, without significant differences between boys and girls. Overall, UR was positively associated with a lower socio-economic status, overweight, skipping breakfast and dinner, a higher contribution of proteins to energy intake (EI), and a lower contribution of simple carbohydrates to EI. Under-reporters aged 3-10 years also had a higher sedentary behaviour and a lower snack-eating frequency. In adolescents, UR was also associated with a less-frequent school canteen attendance, a perception of being overweight, a wish to weigh less, and current and past restrictive diets. In conclusion, under-reporters differ from plausible reporters in several characteristics related to diet, lifestyle, weight status and socio-economic status. Therefore, it is important to consider this differential UR bias when investigating diet-disease associations in children.

\section{Key words: Under-reporting: Dietary surveys: Energy intake: Children: Adolescents}

It is generally accepted that self-reported food intakes underestimate habitual energy intake $(\mathrm{EI})^{(1,2)}$. This issue has been well documented in adults while comparing reported EI either with objective measurements of energy expenditure in small samples (such as the doubly labelled water method) ${ }^{(3)}$, or with estimated $\mathrm{BMR}^{(4)}$. According to the dietary survey tool used ( $24 \mathrm{~h}$ recalls and dietary records) and the population studied, rates of under-reporters in adults have been described to range between 12 and $67 \%$, with a median of about $30 \%{ }^{(2)}$.

This under-reporting (UR) bias is a major concern in nutritional epidemiology, not only when monitoring food and nutrient intakes at the population level, but also when studying relationships between dietary intake and health ${ }^{(5,6)}$. Systematic bias when measuring food intake may indeed attenuate or even reverse the associations studied. It is thus of great importance to identify the cofactors related to UR and to take them into account when interpreting results. Previous studies have suggested that UR was higher among specific subgroups of the population, such as women or obese people, which could lead to differential $\mathrm{UR}^{(3)}$. However, less consensus exists on other correlates, which have been less consistently described, such as age, smoking status, socioeconomic status, physical activity and dietary restraint ${ }^{(5)}$.

Despite a relatively low sensitivity to detect $\mathrm{UR}^{(7)}$, the Goldberg cut-off 2 criterion has often been applied among adults when analysing data from large dietary surveys ${ }^{(3,4,8)}$. The issue of UR has less often been addressed in children due to the lack of such a standardised method adapted to

Abbreviations: EI, energy intake; INCA2, étude Individuelle Nationale des Consommations Alimentaires, 2006-07; IOTF, International Obesity Task Force; PAL, physical activity level; rEI, reported energy intake; UR, under-reporting.

* Corresponding author: S. Lioret, fax +331497738 92, email sandrine.lioretsuteau@deakin.edu.au 
$<18$-year-old subjects. Studies based on the doubly labelled water method have confirmed that UR is also of concern during childhood, with rates increasing with age and varying with weight status ${ }^{(9)}$. Although originally developed for use in adults, the Goldberg cut-off2 has already been applied to children or adolescents in some previous studies, leading to rates of UR of about $1-5 \%$ in children and $11-31 \%$ in adolescents $^{(10-12)}$. This Goldberg cut-off2 has further been adapted for use in children taking into account age-specific values for physical activity, which led to smaller rates of $\mathrm{UR}^{(10,13,14)}$.

This child-specific UR criterion has been applied to the recent nationally representative French INCA2 dietary survey (étude Individuelle Nationale des Consommations Alimentaires, 2006-7) data to explore the extent of UR in children and adolescents, aged, respectively, 3-10 and 11-17 years. We also investigated the relationships between UR and socio-economic status, eating behaviours, food habits, nutritional intake, weight status and weight concern, and sedentary behaviour. To our knowledge, this issue has rarely been addressed in children, based on a national dietary survey and including all these covariates ${ }^{(15)}$.

\section{Subjects and methods}

\section{Subjects and study design}

The French INCA2 dietary survey was carried out between December 2005 and May 2007 by the French Food Safety Agency. This cross-sectional survey was primarily designed to assess food intake patterns in a nationally representative sample of French people. A total of two independent random samples of children aged between 3 and 17 years and adults aged between 18 and 79 years were obtained using a multistage cluster sampling technique. The sampling frame was established from the national census published by the French National Institute of Statistics and of Economic Studies and has been described elsewhere ${ }^{(16-18)}$. A participation rate of $69 \%$ was obtained for subjects $<18$ years, yielding a sample of 1455 children and adolescents.

The INCA2 survey was approved by the French data protection authority (Commission Nationale Informatique et Libertes) and the French national council for statistical information (Conseil National de l'Information Statistique).

\section{Measurements}

Dietary intake was assessed using a $7 \mathrm{~d}$ open-ended estimated food record. A trained and certified investigator delivered the food record and a self-administered questionnaire at each respondent's home and spent $45-60$ min explaining to the parents and their child how to fill them out. Caregivers were encouraged to ask for a copy of the menus corresponding to the meals taken at school. The self-administered questionnaire was adapted to the age of the children. It included questions on eating behaviours, such as school canteen attendance, snack- and fast-food-eating frequencies and vending machine purchase rate. In adolescents aged 11 years or more, weight perception and following a restrictive diet in order to lose weight were also addressed. For children aged 10 years or younger, parents completed the documents, with the help of the child. When aged 11-14 years, the adolescents filled out both the record and the self-administered questionnaire helped by their parents if needed. Young people aged 15-17 years completed them alone. The investigator returned at the respondent's home the following week after the survey was conducted and checked the accuracy of the information reported in the documents.

An additional face-to-face questionnaire, including questions on socio-economic status and lifestyle (notably sedentary behaviour), was administered, partly with the selected child and partly with the responding parent. At this stage of the INCA2 survey, trained interviewers weighed the child in light clothes and without shoes to the nearest $0 \cdot 1 \mathrm{~kg}$ using electronic scales (Terraillon, Chatou, France). Height was measured to the nearest centimetre, in a standing position and without shoes, with a portable gauge.

Dietary data. In the $7 \mathrm{~d}$ food record, subjects reported the type of eating occasion at which each food or drink was consumed, i.e. meals and snacks. 'Snacks' were defined as eating episodes (including the afternoon snack) apart from main meals (i.e. breakfast, lunch and dinner). One line of the record corresponded to one item consumed (food or drink). Participants estimated portion sizes using the Supplementation en VItamines et en Mineraux AntioXydants-validated photographic booklet $^{(19)}$. But if they preferred, they could chose to express the amounts eaten in grams, using their own household measures, or reading the information on the packaging in case of industrial food. Nutritional intake was evaluated using the CIQUAL (French Data Centre on Food Quality) French food composition tables ${ }^{(20,21)}$. In the present study, we assessed the average daily EI (in $\mathrm{kJ} / \mathrm{d}$ ), and the contribution of simple and complex carbohydrates, fat and protein intakes to total EI (expressed in \%). Additional variables were related to the regularity of eating the various meals, taken separately. A relatively low proportion of children ate $<$ six meals during the week of the survey: 6.8 and $26.9 \%$ were the rates for skipping breakfast in children aged $3-10$ and $11-17$ years, respectively; $3 \cdot 8$ and $8.2 \%$ for lunch; 1.8 and $8.8 \%$ for dinner. Consequently, for a given meal, and due to statistical constraints, a child was considered to skip meals if at least one meal out of seven was not eaten over the week.

Under-reporting and over-reporting assessments. UR and over-reporting have been investigated using Goldberg's cutoff 2 criterion ${ }^{(4,22)}$. The principle is to compare the reported EI with total energy expenditure when both are expressed as a multiple of BMR: $95 \%$ confidence limits are used to statistically compare reported EI/BMR with the physical activity level (or total energy expenditure/BMR). Regarding UR, a hypothesis of sedentary lifestyle is set overall for the sample ${ }^{(23)}$ when objective measurements of physical activity are lacking at the individual level. A ratio below this threshold ('cut-off2') has been interpreted as an indicator of implausible individual measurement of EI. 
The two following equations were used:

$$
\begin{aligned}
\operatorname{PAL} \times \exp & {\left[\operatorname{SD}_{\min } \times \frac{(S / 100)}{\sqrt{n}}\right] } \\
& <\mathrm{rEI} / \mathrm{BMR}<\mathrm{PAL} \times \exp \left[\mathrm{SD}_{\max } \times \frac{(S / 100)}{\sqrt{n}}\right],
\end{aligned}
$$

with $n$ being equal to 1 (data on the individual level); $\mathrm{SD}_{\text {min }}= \pm 1.96$ (thresholds corresponding to the lower and upper limits of $95 \% \mathrm{CI}$ ); BMR was estimated according to Schofield's equations ${ }^{(24)}$ taking into account sex, age, body weight and height ${ }^{(25)}$; physical activity level values were adapted to children and corresponded to light physical activity for UR (1.45-1.60, depending on age and sex) and intense levels for over-reporting (1.85-2.05, depending on age and sex $)^{(7,13)}$ (Table 1).

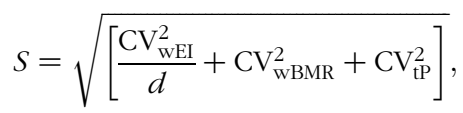

where $d$ is the number of recording days ( $7 \mathrm{~d}$ in most cases); $\mathrm{CV}_{\text {wEI }}$ is $24 \%$ for children $<6$ years old and $23 \%$ for the others $^{(14)}$ and corresponds to the within-subject variation in $\mathrm{EI} ; \mathrm{CV}_{\mathrm{wBMR}}$, the within-subject variation in repeated $\mathrm{BMR}$ measurements (or the precision of estimated compared with measured BMR), was adapted to children, taking into account sex and age ${ }^{(14,24)} ; \mathrm{CV}_{\mathrm{tP}}=15 \%$ and corresponds to the between-subject variation in physical activity level ${ }^{(4,23)}$.

Food habits. In the self-administered questionnaire, the respondents reported the usual snack-eating frequency according to six levels: ' $\geq 4 / \mathrm{d}$ '; ' $2-3$ times/d'; ' $1 / \mathrm{d}$ '; ' $1-6$ times/week'; '<1/week'; 'never'. Usual school canteen attendance was defined in five levels: ' $\geq 5 \mathrm{~d}$ '; ' 3 or $4 \mathrm{~d}$ '; ' 1 or $2 \mathrm{~d}$ '; ' $<1 \mathrm{~d}$ /week'; 'never'. Usual vending machine purchase rate during school days was defined in five levels: 'every day'; '3-4d'; '1-2 d'; ' < 1d/week'; 'never'. Usual fastfood eating frequency was defined in seven levels: 'every day'; '4-5d/week'; '2-3d/week'; '1 d/week'; '1-3d/month'; ' $<1 \mathrm{~d} /$ month'; 'never'. The latter variable was based on the frequency of purchasing foods in fast-food restaurants. Due to statistical constraints (few numbers in the upper-frequency

\begin{tabular}{|c|c|c|c|c|c|}
\hline \multirow{2}{*}{$\begin{array}{l}\text { Age groups } \\
\text { (years) }\end{array}$} & \multirow[b]{2}{*}{$n$} & \multicolumn{2}{|c|}{ Under-reporting } & \multicolumn{2}{|c|}{ Over-reporting } \\
\hline & & $\mathrm{PAL}^{*}$ & Cut-off values & PAL† & Cut-off values \\
\hline \multicolumn{6}{|l|}{ Males } \\
\hline $3-5$ & 75 & 1.45 & 1.00 & 1.60 & $2 \cdot 31$ \\
\hline $6-13$ & 325 & 1.55 & 1.07 & 1.95 & $2 \cdot 82$ \\
\hline $14-18$ & 251 & 1.60 & $1 \cdot 10$ & 2.05 & 2.97 \\
\hline \multicolumn{6}{|l|}{ Females } \\
\hline $3-5$ & 78 & 1.45 & 1.00 & 1.60 & 2.33 \\
\hline $6-13$ & 354 & 1.50 & 1.03 & 1.90 & $2 \cdot 77$ \\
\hline $14-18$ & 298 & 1.45 & 0.99 & 1.85 & $2 \cdot 72$ \\
\hline
\end{tabular}

Table 1. Physical activity level (PAL) and cut-off values used for assessing both under-reporting and over-reporting rates

* These PAL values correspond to sedentary levels of physical activity ${ }^{(13)}$.

†These PAL values correspond to intense levels of physical activity, except in the

3- to 5-year group due to the lack of published value. In this particular age range, the moderate level of physical activity has been used ${ }^{(13)}$. categories), these variables were coded as follows: usual snack-eating frequency - '>1', ' 1 ' and ' $<1 / \mathrm{d}$ '; school canteen attendance - 'regularly' ( $\geq 3 \mathrm{~d} /$ week), 'occasionally or never'; vending machine purchase rate - 'regularly' ( $\geq$ once a week), 'occasionally or never'; fast-food-eating frequency - 'regularly' ( $\geq 1 \mathrm{~d} /$ week), 'occasionally or never'.

Educational level of the responding parent. Socioeconomic status was determined based on the educational level of the parent who helped to answer the questionnaires. This person was the mother in $80.3 \%$ of cases and the father in $18.1 \%$ of cases. The level of education was defined in three categories: 'high'; 'intermediate'; 'low'. 'High' was assigned to university education (under-graduate and post-graduate); 'intermediate' to those who have completed secondary school degree ('O' level or General Certificate of Secondary Education); 'low' to the others.

Sedentary behaviour. Sedentary behaviour was assessed in min/d taking into account the past week as a reference period. The following two variables were considered: (1) the time spent watching television and (2) the time spent in front of a computer or playing video games. The average time for both indices was calculated and weighted from the values reported for each type of day, i.e. school or nonschool days. A global index labelled 'total screen time', equal to the sum of the two previous variables, was then derived into tertiles. We considered two levels of sedentary behaviour: 'high' $\left(T_{3}\right) v$. 'moderate or low' $\left(T_{2}\right.$ or $\left.T_{1}\right)$.

Overweight status. Overweight (including obesity) was estimated according to the International Obesity Task Force age- and sex-specific child BMI (weight $/$ height $^{2}$, in $\mathrm{kg} / \mathrm{m}^{2}$ ) cut-off points ${ }^{(26)}$.

Weight concern. All children self-reported if they were following a restrictive diet (in order to maintain or to lose weight, yes or no). Adolescents aged 11-17 years answered three additional questions: perception of his/her weight ('overweight' or not); wish with regard to their weight ('wish to weigh less' or 'satisfied' or 'wish to weigh more'); attempts at weight loss/stabilisation over the last year (yes or no).

\section{Statistical analysis}

All analyses were performed using the statistical software package SAS (version 9.1; SAS Institute, Cary, NC, USA). Data were weighted for unequal sampling probabilities and for differential non-responses by region, conglomerate size, age, sex, occupation of the head of the household, household size and season. $\chi^{2}$ tests and Student's $t$ test were used to compare frequencies and means, respectively. A $P$ value of $<0.05$ was used as the threshold for significance. All eighteen variables previously described (educational level, sedentary behaviour, overweight, weight-concern variables, eating behaviours, food habits and nutrient intake) were compared by age category (children aged 3-10 years and adolescents aged 11-17 years). An additional stratification for sex was not maintained because relationships between UR and covariates were overall the same in boys and girls (results not shown). Unconditional sex- and age-adjusted logistic regressions (age, continuous) were then performed to investigate the associations 
between UR as the dependent variable and each of the eighteen variables. Finally, we performed a multivariate age- and sex-adjusted stepwise logistic regression where UR was still the dependent variable and where all the eighteen factors were introduced simultaneously: critical $P$ values that selected variables were set at $P=0 \cdot 10$.

\section{Results}

\section{Characteristics of the study population}

Characteristics of the study sample are presented by age in Table 2. Rates of under-reporters did not differ significantly between boys and girls $(5.3$ and $4.4 \%$, respectively, in boys and girls aged $3-10$ years, and 26.3 and $25.8 \%$, respectively, in boys and girls aged $11-17$ years). The rate of under-reporters was almost sixfold higher among adolescents. The following variables also increased with age: sedentary screen behaviour, following a restrictive diet, skipping meals (breakfast, lunch or dinner), school canteen attendance, and both fast-food eating and vending machine purchase frequencies. Adolescents reported fewer snacking occasions (afternoon snack included) than did children $<11$ years. Overweight prevalence was about the same in both age categories. Weight-concern-related variables were only collected among adolescents aged 11 years or more: nearly half of them wished to weigh less; $41 \%$ tried either to stabilise or lose weight over the past year; about a quarter of the sample felt overweight. Among the latter, 37.4 (95\% CI 29.8, 45.0)\% were truly overweight, while this rate was $5 \cdot 2(95 \%$ CI $2 \cdot 8,7 \cdot 6) \%$ in their counterparts who did not perceive themselves overweight. In addition, 33.4 (95\% CI $24.0,42.7) \%$ of the non-overweight adolescents who perceived themselves overweight under-reported their EI according to the definition chosen; this rate was $60 \cdot 0$ (95\% CI $47.9,72.0) \%$ in adolescents perceiving themselves as overweight and being truly overweight.

In total, $1 \cdot 4 \%$ of the children aged 3-10 years and none of the 11-17 years were identified as over-reporters. These rates were too small to allow more in-depth analyses of the over-reporters (lack of statistical power). Over-reporters aged 3-10 years were not excluded from the analyses and were considered as non-under-reporters.

Analyses involving weight status were restricted to the subjects with available measurements (seventy-four missing values). However, the children excluded from the multivariate analyses did not differ from the others with respect to sociodemographical characteristics (data not shown).

\section{Relationships between under-reporting and covariates}

Although not retained in the multivariate stepwise models, parental educational level was inversely related to UR in the age- and sex-adjusted analyses (Table 3). Sedentary behaviour was positively associated with UR in children aged 3-10 years (multivariate OR for low-middle $v$. high sedentary behaviour $\mathrm{OR}_{\text {low-middle/high }} 0 \cdot 30,95 \%$ CI $0 \cdot 12,0 \cdot 72$ ). Overall, underreporters were more likely to be overweight: multivariate

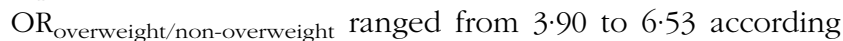

to the age category. In adolescents, all covariates describing weight perception, wishes regarding weight, current or past restrictive diets were significantly associated with UR. However, only the variable describing wishes with regard to weight status remained significantly related in the final multivariate model (multivariate $\mathrm{OR}_{\text {wish to weigh less/satisfied or wish to weigh more }}$ $2 \cdot 32,95 \%$ CI $1 \cdot 36,3 \cdot 95$ ), indicating a high collinearity between all these covariates. In children, UR was positively associated with skipping breakfast; in adolescents, it was also the case with skipping lunch and dinner. Under-reporters also reported less-frequent snack-eating occasions. Both fast-food-eating and vending machine purchase frequencies were not significantly associated with UR. Conversely, school canteen attendance was less frequent among adolescent under-reporters in age- and sex-adjusted models only ( $\mathrm{OR}_{\mathrm{occasionally} \mathrm{or} \mathrm{never/regularly}}$ $1 \cdot 61,95 \%$ CI $1 \cdot 05,2 \cdot 47)$.

As expected, average EI was significantly smaller $(P<0.0001)$ among under-reporters: 4538 (SD 1164) and $5694(\mathrm{sD} 1624) \mathrm{kJ} / \mathrm{d}$ in 3- to 10- and 11- to 14-year underreporters; $7013(\mathrm{SD} 1645)$ and $8742(\mathrm{SD} 2001) \mathrm{kJ} / \mathrm{d}$ in 3- to 10 - and 11- to 14-year non-under-reporters (results not shown). Only proteins' contribution to EI remained significantly and positively associated with UR in multivariate analyses. In age- and sex-adjusted analyses, under-reporters were also characterised by a smaller contribution of simple carbohydrates to EI (Table 3). Other analyses further indicated that the consumption of pastries and cakes, ice cream, chocolate, sugar and confectionery, and sweetened beverages were more than twofold smaller in under-reporters in both age ranges $(P<0 \cdot 0001)$ (data not shown).

\section{Discussion}

The INCA2 survey included comprehensive factors related to food intake, weight status and perception, and socio-economic status, allowing a broad investigation on UR covariates and giving original insights into this issue in children. Other strengths of the present study are the national representativeness of the sample and the large age range considered, enabling comparisons between children and adolescents. Food consumption was recorded over $7 \mathrm{~d}$, which was an advantage to take into account the day-to-day variability of intakes $^{(9)}$. The definition of UR was also strengthened by the fact that weight and height were objectively measured.

Limitations of our findings have to be acknowledged. Standardised definition of UR (and over-reporting) in children is lacking, and we could not compare the present results with biomarkers (such as doubly labelled water or urinary $\mathrm{N}$ excretion). In addition, our assessment of UR status would have been improved with an objective measurement of physical activity (such as accelerometry) or at least a validated questionnaire of physical activity, both not available in the INCA2 dataset. Indeed, the threshold used to identify under-reporters was based on a hypothesis of sedentary lifestyle for all children. One consequence is that some people with high energy expenditure (and thus higher energy requirements) might have been classified as plausible reporters, although they are under-reporters. This limitation has led some authors 
Table 2. Characteristics of the sample*

(Percentages, $95 \%$ confidence intervals, mean values and standard deviations)

\begin{tabular}{|c|c|c|c|c|c|}
\hline & \multicolumn{2}{|c|}{$3-10$ years } & \multicolumn{2}{|c|}{$11-17$ years } & \multirow[b]{2}{*}{$P$} \\
\hline & $\%$ & $95 \% \mathrm{Cl}$ & $\%$ & $95 \% \mathrm{Cl}$ & \\
\hline \multicolumn{6}{|l|}{ Sex } \\
\hline$n$ & \multicolumn{2}{|c|}{574} & \multicolumn{2}{|c|}{881} & \\
\hline Males & 53.4 & $49 \cdot 3,57 \cdot 5$ & $49 \cdot 2$ & $45 \cdot 0,53 \cdot 4$ & $0 \cdot 16$ \\
\hline Females & $46 \cdot 6$ & $42 \cdot 0,51 \cdot 1$ & $50 \cdot 8$ & $46 \cdot 1,55 \cdot 4$ & \\
\hline \multicolumn{6}{|l|}{ Reporting status } \\
\hline$n$ & \multicolumn{2}{|c|}{541} & \multicolumn{2}{|c|}{840} & \\
\hline Under-reporters & 4.9 & $3 \cdot 2,6 \cdot 5$ & $26 \cdot 0$ & $22.1,29.9$ & $<0.0001$ \\
\hline Plausible reporters & $93 \cdot 7$ & $91 \cdot 8,95 \cdot 7$ & 74.0 & $70 \cdot 1,77 \cdot 9$ & \\
\hline Over-reporters & 1.4 & $0.4,2.3$ & & 0 & ND \\
\hline \multicolumn{6}{|l|}{ Educational level } \\
\hline$n$ & \multicolumn{2}{|c|}{572} & \multicolumn{2}{|c|}{875} & \\
\hline Low & $11 \cdot 0$ & $8 \cdot 0,13 \cdot 9$ & $19 \cdot 1$ & $14 \cdot 6,23 \cdot 6$ & \\
\hline Middle & $50 \cdot 5$ & $46 \cdot 2,54 \cdot 7$ & $52 \cdot 4$ & $48 \cdot 0,56 \cdot 8$ & \\
\hline High & 38.5 & $34.3,42 \cdot 9$ & 28.5 & $24 \cdot 8,32 \cdot 2$ & 0.0003 \\
\hline Total screen time & & & & & \\
\hline$n$ & & 574 & & 378 & \\
\hline Mean $(\min / \mathrm{d})$ & 132.1 & & 209.5 & & \\
\hline $\mathrm{SD}(\mathrm{min} / \mathrm{d})$ & $126 \cdot 0$ & & 121.9 & & $<0.0001$ \\
\hline Weight status & & & & & \\
\hline$n$ & & 541 & & 340 & \\
\hline Non-overweight & $85 \cdot 8$ & $82 \cdot 7,89 \cdot 0$ & $86 \cdot 5$ & $83.6,89.5$ & \\
\hline Overweight & $14 \cdot 2$ & $11 \cdot 3,17 \cdot 0$ & 13.5 & $10 \cdot 7,16 \cdot 2$ & 0.71 \\
\hline Current restrictive diet & & & & & \\
\hline$n$ & & 574 & & 381 & \\
\hline Yes & 1.0 & $0.2,1.8$ & $7 \cdot 8$ & $5 \cdot 7,10 \cdot 0$ & $<0.0001$ \\
\hline No & $99 \cdot 0$ & $98 \cdot 2,99 \cdot 8$ & $92 \cdot 2$ & $90 \cdot 0,94 \cdot 3$ & \\
\hline Tried to stabilise or lose we & & & & & \\
\hline$n$ & & ND & & 364 & \\
\hline Yes & & & $40 \cdot 7$ & $36 \cdot 6,44 \cdot 8$ & \\
\hline No & & & $59 \cdot 3$ & $54.9,63.8$ & \\
\hline Weight perception & & & & & \\
\hline$n$ & & ND & & 367 & \\
\hline Non-overweight & & & $73 \cdot 8$ & $70 \cdot 2,77 \cdot 6$ & \\
\hline Overweight & & & $26 \cdot 2$ & $22 \cdot 8,29.5$ & \\
\hline Wish with regard to the weis & & & & & \\
\hline$n$ & & ND & & 366 & \\
\hline Do not wish to weigh less & & & 58.5 & $54 \cdot 2,62 \cdot 8$ & \\
\hline Wish to weigh less & & & 41.5 & $37.5,45 \cdot 5$ & \\
\hline Regularity of eating breakfa & & & & & \\
\hline$n$ & & 574 & & 381 & \\
\hline$<7 \mathrm{~d} /$ week & $13 \cdot 3$ & $10 \cdot 5,16 \cdot 2$ & 39.5 & $35 \cdot 2,43 \cdot 7$ & $<0.0001$ \\
\hline $7 \mathrm{~d} /$ week & $86 \cdot 7$ & $83.5,89.9$ & 60.5 & $56 \cdot 0,65 \cdot 1$ & \\
\hline Regularity of eating lunch & & & & & \\
\hline$n$ & & 574 & & 381 & \\
\hline$<7 \mathrm{~d} /$ week & $11 \cdot 3$ & $8 \cdot 3,14 \cdot 2$ & $16 \cdot 7$ & $13 \cdot 9,19 \cdot 5$ & 0.02 \\
\hline $7 \mathrm{~d} /$ week & 88.7 & $85 \cdot 5,92 \cdot 0$ & $83 \cdot 3$ & $80 \cdot 3,86 \cdot 3$ & \\
\hline Regularity of eating dinner & & & & & \\
\hline$n$ & & 574 & & 381 & \\
\hline$<7 \mathrm{~d} /$ week & $10 \cdot 8$ & $8 \cdot 1,13 \cdot 4$ & $20 \cdot 6$ & $16 \cdot 4,24 \cdot 7$ & 0.0001 \\
\hline $7 \mathrm{~d} /$ week & 89.2 & $86 \cdot 4,92 \cdot 0$ & 79.4 & $75 \cdot 3,83 \cdot 6$ & \\
\hline Snack-eating frequency & & & & & \\
\hline$n$ & & 552 & & 346 & \\
\hline$<1 / \mathrm{d}$ & $8 \cdot 7$ & $6.5,11 \cdot 0$ & $20 \cdot 1$ & $16 \cdot 7,23 \cdot 5$ & \\
\hline $1 / d$ & $52 \cdot 2$ & $47 \cdot 9,56 \cdot 5$ & $42 \cdot 2$ & $38.5,46 \cdot 0$ & \\
\hline$>1 / d$ & $39 \cdot 1$ & $34 \cdot 8,43 \cdot 4$ & $37 \cdot 7$ & $33 \cdot 1,42 \cdot 2$ & $<0.0001$ \\
\hline School canteen attendance & & & & & \\
\hline$n$ & & 574 & & 381 & \\
\hline Regularly & $48 \cdot 7$ & $44 \cdot 0,53 \cdot 4$ & $62 \cdot 2$ & $57 \cdot 8,66 \cdot 7$ & 0.0001 \\
\hline Occasionally or never & $51 \cdot 3$ & $46 \cdot 6,56 \cdot 0$ & 37.8 & $33 \cdot 3,42 \cdot 2$ & \\
\hline Fast-food-eating frequency & & & & & \\
\hline$n$ & & 567 & & 855 & \\
\hline Regularly & $2 \cdot 6$ & $1 \cdot 4,3 \cdot 8$ & 9.4 & $7 \cdot 5,11 \cdot 3$ & $<0.0001$ \\
\hline Occasionally or never & $97 \cdot 4$ & $96 \cdot 1,98 \cdot 7$ & $90 \cdot 6$ & $88 \cdot 4,92 \cdot 8$ & \\
\hline Vending machine purchase & & & & & \\
\hline$n$ & & 574 & & 381 & \\
\hline Regularly & $2 \cdot 6$ & $1 \cdot 1,4 \cdot 1$ & $9 \cdot 8$ & $8 \cdot 0,11 \cdot 7$ & $<0.0001$ \\
\hline Occasionally or never & $97 \cdot 4$ & $96 \cdot 2,98 \cdot 7$ & $90 \cdot 2$ & $87 \cdot 7,92 \cdot 6$ & \\
\hline
\end{tabular}


Table 2. Continued

\begin{tabular}{|c|c|c|c|c|c|}
\hline & \multicolumn{2}{|c|}{$3-10$ years } & \multicolumn{2}{|c|}{$11-17$ years } & \multirow[b]{2}{*}{$P$} \\
\hline & $\%$ & $95 \% \mathrm{Cl}$ & $\%$ & $95 \% \mathrm{Cl}$ & \\
\hline \multicolumn{6}{|c|}{ Contribution of proteins to energy intake } \\
\hline$n$ & & 574 & & 881 & \\
\hline Mean (\%) & $15 \cdot 3$ & & $15 \cdot 6$ & & \\
\hline SD $(\%)$ & $2 \cdot 8$ & & $2 \cdot 2$ & & 0.028 \\
\hline \multicolumn{6}{|c|}{ Contribution of fats to energy intake } \\
\hline$n$ & & 574 & & 881 & \\
\hline Mean (\%) & 38.6 & & $37 \cdot 3$ & & 0.0001 \\
\hline SD (\%) & $5 \cdot 3$ & & 4.5 & & \\
\hline \multicolumn{6}{|c|}{ Contribution of simple carbohydrates to energy intake } \\
\hline$n$ & & 574 & & 881 & \\
\hline Mean (\%) & 23.8 & & $20 \cdot 7$ & & $<0.0001$ \\
\hline $\mathrm{SD}(\%)$ & 5.4 & & 4.6 & & \\
\hline \multicolumn{6}{|c|}{ Contribution of complex carbohydrates to energy intake } \\
\hline$n$ & & 574 & & 881 & \\
\hline Mean (\%) & $21 \cdot 1$ & & $25 \cdot 1$ & & $<0.0001$ \\
\hline SD (\%) & $5 \cdot 2$ & & 4.6 & & \\
\hline
\end{tabular}

to prefer the terms 'low-energy reporters' ${ }^{,(7)}$ or 'non-plausible reporters, ${ }^{, 14)}$ rather than 'under-reporters'. Negligible proportions of over-reporting were found in the present study, but this result should also be interpreted with caution because the physical activity level values for heavy habitual physical activity $^{(13)}$ were not derived from experiments, but were rather arbitrarily chosen ${ }^{(15)}$.

Thus, rates of misreporting are not easily comparable with other studies, since standard measurements of both UR and over-reporting still have to be validated. Yet, the rates we derived for UR were in the same range as those estimated based on the same definition in two observational studies in children $^{(10,14)}$. Interestingly, the proportion of under-reporters was not statistically different in children of the previous INCA1 survey $^{(27,28)}$, performed in 1998-9 (results not shown).

The increasing bias towards UR as the children get older has often been described, and several reasons have been suggested $^{(9,29,30)}$. First, the person completing the dietary record varies with age: while dietary intake is usually reported by a proxy person for the youngest children, it is the adolescent himself/herself who usually participates in the survey. Bias towards UR might be larger when the concerned persons are directly involved in the survey, along with a higher propensity to report intakes more consistent with dietary guidelines, particularly when they are overweight ${ }^{(31)}$. Adolescents are indeed sensitive to social desirability. Second, eating behaviours and food patterns are known to be less structured during adolescence ${ }^{(15)}$. Foods are more often eaten outside the home, particularly snacks, which are more prone to be forgotten; skipping meals and, more generally, irregularity of eating occasions are more widespread in this particular population, which impairs memorisation and good reflection of eating events ${ }^{(30,32)}$. In accordance with this overall hypothesis, attending school canteen regularly, which contributes to structured eating behaviours, was shown to be inversely associated with UR in our data. It should also be noted that the $7 \mathrm{~d}$ food record might not be the most suitable method for collecting food intake in adolescents. The latter are likely to be less compliant in completing the record - which is time consuming - as part of their general reluctance in being involved in initiatives taken by adults. A study by Moreno et $a l .{ }^{(33)}$ has shown that UR rates in adolescents increased with the number of collecting days, from $3.9 \%$ over $3 \mathrm{~d}$ to $7 \cdot 8 \%$ over $7 \mathrm{~d}$ in boys; and from $14.2 \%$ over $3 \mathrm{~d}$ to $20.3 \%$ over $7 \mathrm{~d}$ in girls. Yet, the ideal method for collecting dietary intakes in adolescents is still under debate ${ }^{(34)}$. It has been recommended to use two or three repeated $24 \mathrm{~h}$ recalls over non-consecutive days from the age of 15 years onwards ${ }^{(35)}$, but this alternative is still under consideration ${ }^{(36)}$.

Our findings did not show significant differences by sex: studies have not been consistent regarding this issue. Some have observed higher rates in adolescent girls ${ }^{(5,14,10,33)}$, but others have not ${ }^{(30)}$. Consensus is also lacking regarding the socio-economic correlates of $\mathrm{UR}^{(3,5)}$. Nevertheless, most studies performed in adults have shown that UR is more frequent in the lower educational groups, probably due to both the literacy requirements for completing records and questionnaires and a lower interest in health and nutrition matter ${ }^{(37)}$. The present results further showed that parental education level was not retained in the stepwise multivariate regressions, which is probably due to the high collinearity between education and both sedentary behaviour and weight status ${ }^{(38)}$. Our findings also suggested that under-reporters aged 3-10 years were likely to be more sedentary (screen behaviour), compared with their non-under-reporter counterparts. We are not aware of any study having examined this issue, and thus comparison with other results was not possible.

Importantly, the low EI reported by some children may not entirely be due to under-recording, but may reflect attempts to lose weight, and thus real under-eating ${ }^{(5)}$. This hypothesis was well illustrated by our findings, which showed positive associations between UR and weight-related 
Table 3. Under-reporting according to sociodemographical, anthropometrical, behavioural and nutritional variables (Age- and sex-adjusted and multivariate odds ratios and $95 \%$ confidence intervals)

\begin{tabular}{|c|c|c|c|c|c|c|c|c|}
\hline & \multicolumn{4}{|c|}{$3-10$ years } & \multicolumn{4}{|c|}{$11-17$ years } \\
\hline & \multicolumn{2}{|c|}{$\begin{array}{c}\text { Age- and } \\
\text { sex-adjusted }\end{array}$} & \multicolumn{2}{|c|}{ Multivariate $†$} & \multicolumn{2}{|c|}{$\begin{array}{c}\text { Age- and } \\
\text { sex-adjusted }\end{array}$} & \multicolumn{2}{|c|}{ Multivariate $†$} \\
\hline & OR & $95 \% \mathrm{Cl}$ & OR & $95 \% \mathrm{Cl}$ & OR & $95 \% \mathrm{Cl}$ & OR & $95 \% \mathrm{Cl}$ \\
\hline \multicolumn{9}{|l|}{ Educational level } \\
\hline$n$ & & 539 & & & & 835 & & \\
\hline Low & $5 \cdot 21$ & $1 \cdot 25,21 \cdot 80$ & & & 1.90 & $0.97,3.72$ & & \\
\hline Middle & 2.52 & $0.72,8.87$ & & & $1 \cdot 28$ & $0.82,2 \cdot 01$ & & \\
\hline High & & 1 & & & & 1 & & \\
\hline$P$ (linear trend) & & 0.02 & & & & .06 & & \\
\hline \multicolumn{9}{|l|}{ Sedentary behaviour } \\
\hline$n$ & & 541 & & 519 & & 837 & & \\
\hline Low-middle & 0.30 & $0.12,0.72$ & 0.27 & $0.09,0.80$ & 0.70 & $0.46,1.07$ & & \\
\hline High & & 1 & & 1 & & 1 & & \\
\hline$P$ & & 0.008 & & 0.02 & & .10 & & \\
\hline \multicolumn{9}{|l|}{ Weight status } \\
\hline$n$ & & 541 & & 519 & & 840 & & 825 \\
\hline Non-overweight & & 1 & & 1 & & 1 & & 1 \\
\hline Overweight & 6.04 & $2 \cdot 55,14.33$ & 6.53 & $2.44,17.56$ & $6 \cdot 00$ & $3.82,9.42$ & 3.90 & $2 \cdot 25,6 \cdot 76$ \\
\hline$P$ & & $<0.0001$ & & $<0.0001$ & & .0001 & & $<0.0001$ \\
\hline \multicolumn{9}{|l|}{ Weight perception } \\
\hline$n$ & & ND & & & & 327 & & \\
\hline Non-overweight & & & & & & 1 & & \\
\hline Overweight & & & & & 3.44 & $2 \cdot 22,5.33$ & & \\
\hline$P$ & & & & & & 0001 & & \\
\hline \multicolumn{9}{|l|}{ Wish with regard to the weight } \\
\hline$n$ & & ND & & & & 325 & & 825 \\
\hline Satisfied or wish to weigh more & & & & & & 1 & & 1 \\
\hline Wish to weigh less & & & & & 3.43 & $2 \cdot 24,5 \cdot 24$ & 2.32 & $1.36,3.95$ \\
\hline$P$ & & & & & & .0001 & & 0.002 \\
\hline \multicolumn{9}{|l|}{ Current restrictive diet } \\
\hline$n$ & & ND & & & & 840 & & \\
\hline No & & & & & & 1 & & \\
\hline Yes & & & & & 3.76 & $2 \cdot 02,6 \cdot 98$ & & \\
\hline$P$ & & & & & & .0001 & & \\
\hline Tried to stabilise or lose weight ove & e last & ear & & & & & & \\
\hline$n$ & & ND & & & & 323 & & \\
\hline No & & & & & & 1 & & \\
\hline Yes & & & & & $2 \cdot 91$ & $1.92,4.40$ & & \\
\hline$P$ & & & & & & .0001 & & \\
\hline Regularity of eating breakfast & & & & & & & & \\
\hline$n$ & & 541 & & 519 & & 840 & & 825 \\
\hline $7 \mathrm{~d}$ over the week & & 1 & & 1 & & 1 & & 1 \\
\hline$<7 d$ & 4.56 & $1.77,11.73$ & 4.24 & $1.26,14.31$ & 3.73 & $2.46,5.66$ & 3.62 & $2 \cdot 27,5 \cdot 77$ \\
\hline$P$ & & 0.002 & & 0.02 & & .0001 & & $<0.0001$ \\
\hline Regularity of eating lunch & & & & & & & & \\
\hline$n$ & & 541 & & & & 840 & & 825 \\
\hline $7 \mathrm{~d}$ over the week & & 1 & & & & 1 & & 1 \\
\hline$<7 d$ & 1.93 & $0.69,5.40$ & & & 2.90 & $1.80,4.66$ & 2.07 & $1.14,3.76$ \\
\hline$P$ & & 0.21 & & & & .0001 & & 0.02 \\
\hline Regularity of eating dinner & & & & & & & & \\
\hline$n$ & & 541 & & & & 840 & & 825 \\
\hline $7 \mathrm{~d}$ over the week & & 1 & & & & 1 & & 1 \\
\hline$<7 d$ & 3.90 & $1.62,9.37$ & & & $3 \cdot 19$ & $1.87,5.44$ & 2.90 & $1.69,4.99$ \\
\hline$P$ & & 0.003 & & & & .0001 & & $<0.0001$ \\
\hline Snack-eating frequency & & & & & & & & \\
\hline$n$ & & 519 & & 519 & & 305 & & \\
\hline$<1 / \mathrm{d}$ & 3.44 & $1 \cdot 28,9 \cdot 22$ & $4 \cdot 36$ & $1.31,14.56$ & 1.59 & $0.95,2.67$ & & \\
\hline $1 / \mathrm{d}$ & & 1 & & 1 & & 1 & & \\
\hline$>1 / d$ & 0.56 & $0.18,1.77$ & 0.64 & $0.17,2.49$ & 0.88 & $0.54,1.44$ & & \\
\hline$P$ & & 0.02 & & 0.03 & & .11 & & \\
\hline School canteen attendance & & & & & & & & \\
\hline$n$ & & 541 & & & & 840 & & \\
\hline Regularly & & 1 & & & & 1 & & \\
\hline Occasionally or never & 1.06 & $0.44,2.55$ & & & 1.61 & $1.05,2.47$ & & \\
\hline$P$ & & 0.89 & & & & .03 & & \\
\hline
\end{tabular}




\begin{tabular}{|c|c|c|c|c|c|c|c|c|}
\hline & \multicolumn{4}{|c|}{$3-10$ years } & \multicolumn{4}{|c|}{$11-17$ years } \\
\hline & \multicolumn{2}{|c|}{$\begin{array}{l}\text { Age- and } \\
\text { sex-adjusted }\end{array}$} & \multicolumn{2}{|c|}{ Multivariate $†$} & \multicolumn{2}{|c|}{$\begin{array}{l}\text { Age- and } \\
\text { sex-adjusted }^{\star}\end{array}$} & \multicolumn{2}{|c|}{ Multivariate† } \\
\hline & OR & $95 \% \mathrm{Cl}$ & OR & $95 \% \mathrm{Cl}$ & OR & $95 \% \mathrm{Cl}$ & OR & $95 \% \mathrm{Cl}$ \\
\hline \multicolumn{9}{|l|}{ Fast-food-eating frequency } \\
\hline$n$ & & 534 & & & & 14 & & \\
\hline Occasionally or never & & 1 & & & & 1 & & \\
\hline Regularly & $1 \cdot 15$ & $0.14,9 \cdot 27$ & & & $1 \cdot 10$ & $0.61,1.97$ & & \\
\hline$P$ & & 0.90 & & & & 75 & & \\
\hline \multicolumn{9}{|c|}{ Vending machine purchase frequency } \\
\hline$n$ & & 541 & & & & 40 & & \\
\hline Occasionally or never & & 1 & & & & 1 & & \\
\hline Regularly & 0.96 & $0.11,8.43$ & & & 0.99 & $0.52,1.88$ & & \\
\hline$P$ & & 0.97 & & & & 98 & & \\
\hline \multicolumn{9}{|c|}{ Contribution of proteins to energy intake } \\
\hline$n$ & & 541 & & 519 & & 40 & & 825 \\
\hline$\%$ & 1.56 & $1.28,1.92$ & 1.55 & $1.26,1.92$ & 1.31 & $1.21,1.43$ & 1.35 & $1.22,1.49$ \\
\hline$P$ & & 0.0001 & & $<0.0001$ & & 0001 & & $<0.0001$ \\
\hline \multicolumn{9}{|c|}{ Contribution of fats to energy intake } \\
\hline$n$ & & 541 & & & & 40 & & \\
\hline$\%$ & 0.96 & $0.86,1.06$ & & & 1.03 & $0.99,1.07$ & & \\
\hline$P$ & & 0.39 & & & & 18 & & \\
\hline \multicolumn{9}{|c|}{ Contribution of simple carbohydrates to energy intake } \\
\hline$n$ & & 541 & & & & 40 & & \\
\hline$\%$ & 0.90 & $0.79,1.00$ & & & 0.91 & $0.88,0.95$ & & \\
\hline$P$ & & 0.04 & & & & 0001 & & \\
\hline \multicolumn{9}{|c|}{ Contribution of complex carbohydrates to energy intake } \\
\hline$n$ & & 541 & & & & 40 & & \\
\hline$\%$ & 1.01 & $0.87,1.17$ & & & 1.00 & $0.96,1.05$ & & \\
\hline$P$ & & 0.90 & & & & .8 & & \\
\hline
\end{tabular}

ND, not detectable.

*Age- and sex-adjusted logistic regression analyses.

† Stepwise multivariate logistic regression analysis adjusted for sex and age (continuous). Only the OR of the variables selected by the stepwise logistic regression are given.

factors, such as weight status, perception, feelings, wishes and dietary restrictive behaviours. The present results further highlighted that UR EI (and/or under-eating) was mainly associated with being truly overweight, rather than wrongly perceiving oneself overweight. Other authors have also suggested that UR of dietary intake was positively associated with body fatness ${ }^{(10,30,31,39-43)}$, weight consciousness and dieting $^{(15,44)}$. The pattern of skipping meals has already been described in UR children, as well as the fewer snack-eating occasions ${ }^{(10,31,37)}$. Again, we cannot exclude that these eating behaviours were induced by overweight and dieting ${ }^{(45)}$. Therefore, among low-energy reporters identified with the Goldberg definition, those who are dieting should be distinguished from those who are under-recording.

Whatever the reasons are, our findings on macronutrient and food intakes also suggested that omission and/or restraint are more likely to concern sweet and/or fatty foods. That would indeed partly explain why low-energy reporters had a lower contribution of simple carbohydrates to EI and a higher contribution of proteins to EI, as already observed in other datasets ${ }^{(3,5,10,31)}$. In contrast, Fisher et al. ${ }^{(43)}$ found no differences in macronutrient reporting among 4- to 11-yearold children who were identified as under-reporters, accurate reporters and over-reporters. Further analyses that would compare patterns derived from the overall diet between under-reporters and non-under-reporters should help to further explore this issue.

Understanding the error in self-report data may help both improving data collection and analysing the relationships between dietary intake and health outcomes ${ }^{(46)}$. Maintaining or excluding subjects identified as under-reporters in the analyses is still a matter of debate ${ }^{(2,6)}$. The most appropriate analysis choices to overcome the potentially induced bias in nutritional epidemiological studies should depend on the objectives of the study.

On the one hand, when the main issue is to describe eating patterns in a national representative sample for example, excluding under-reporters is likely to induce another kind of bias (selection bias) ${ }^{(3)}$. Indeed, the present results support the idea that non-plausible reporters differ from plausible reporters for many covariates related to sociodemographical background and dietary intake. In addition, excluding people who are dieting and thus who are true under-eaters rather than under-reporters may also distort the results if the aim is to measure as closely as possible the 'true' intakes at the group level. Consequently, when the aim of the analyses is monitoring food intake at the population level, our recommendation would rather be to maintain the identified misreporters in the sample. It could, however, be worth to exclude the outliers with extreme values for EI. 
On the other hand, it is probably worth identifying the under-reporters when the main issue is to investigate the aetiology of health outcomes related to food intake. For instance, including implausible records in the analyses has been shown in few studies ${ }^{(31,37)}$ to result in either weak, non-significant or misleading associations between dietary intake and obesity. To avoid selection bias by discarding a large part of the sample (when excluding under-reporters), it has been suggested to adjust the analyses for either reporting status or variables associated with UR (such as dietary restraint, weight dissatisfaction, etc. $)^{(31)}$. From a methodological point of view, it is certainly worthwhile to compare these complementary approaches (exclusion of under-reporters $v$. adjustment for UR covariates) when studying the relationships between dietary intake and health status. Indeed, studies that have addressed this issue are sparse, particularly in children.

In conclusion, if we put aside the discussion on UR $v$. under-eating, our findings suggest that low-energy reporters are characterised by a relatively less favourable profile, in terms of education, weight status, sedentary behaviour and eating behaviours. People with low educational background and thus low knowledge on nutrition and health are likely to be both less interested and less compliant in recording food intake. In other respects, due to socially desirable behaviour, people with poor health-related behaviours are more likely to omit reporting the foods than less fit dietary guidelines. Consequently, it is important to consider this differential UR bias when investigating diet-disease associations in children and adolescents.

\section{Acknowledgements}

S. L. designed the study, analysed and interpreted the data and wrote the manuscript. M. Ba. contributed to the literature search and the statistical analyses. M. T. and I. H. contributed to the conceptualisation of the study, interpretation of the results and editing of the manuscript. L. L., C. D., A. D. and M. Be. contributed to the design of the survey and the data collection, and together with B. M., helped to write the manuscript. The study was supported by the French Food Safety Agency. All authors have read and approved the final manuscript. None of the authors had a conflict of interest.

\section{References}

1. Black AE, Prentice AM, Goldberg GR, et al. (1993) Measurements of total energy expenditure provide insights into the validity of dietary measurements of energy intake. $J \mathrm{Am}$ Diet Assoc 93, 572-579.

2. Poslusna K, Ruprich J, de Vries JH, et al. (2009) Misreporting of energy and micronutrient intake estimated by food records and 24 hour recalls, control and adjustment methods in practice. Br J Nutr 101, Suppl. 2, S73-S85.

3. Livingstone MB \& Black AE (2003) Markers of the validity of reported energy intake. J Nutr 133, Suppl. 3, S895-S920.

4. Goldberg GR, Black AE, Jebb SA, et al. (1991) Critical evaluation of energy intake data using fundamental principles of energy physiology: 1 . Derivation of cut-off limits to identify under-recording. Eur J Clin Nutr 45, 569-581.
5. Macdiarmid J \& Blundell J (1998) Assessing dietary intake: who, what and why of under-reporting. Nutr Res Rev $\mathbf{1 1}$ 231-253.

6. Nielsen SJ \& Adair L (2007) An alternative to dietary data exclusions. J Am Diet Assoc 107, 792-799.

7. Black AE (2000) The sensitivity and specificity of the Goldberg cut-off for EI:BMR for identifying diet reports of poor validity. Eur J Clin Nutr 54, 395-404.

8. Black AE (2000) Critical evaluation of energy intake using the Goldberg cut-off for energy intake:basal metabolic rate. A practical guide to its calculation, use and limitations. Int J Obes Relat Metab Disord 24, 1119-1130.

9. Livingstone MB \& Robson PJ (2000) Measurement of dietary intake in children. Proc Nutr Soc 59, 279-293.

10. Kersting M, Sichert-Hellert W, Lausen B, et al. (1998) Energy intake of 1 to 18 year old German children and adolescents. Z Ernabrungswiss 37, 47-55.

11. Matthys C, De Henauw S, Devos C, et al. (2003) Estimated energy intake, macronutrient intake and meal pattern of Flemish adolescents. Eur J Clin Nutr 57, 366-375.

12. Dollman J, Ridley K, Magarey A, et al. (2007) Dietary intake, physical activity and TV viewing as mediators of the association of socioeconomic status with body composition: a cross-sectional analysis of Australian youth. Int J Obes 31, 45-52.

13. Torun B, Davies PS, Livingstone MB, et al. (1996) Energy requirements and dietary energy recommendations for children and adolescents 1 to 18 years old. Eur J Clin Nutr 50, Suppl. 1, S37-S80; discussion S-1.

14. Sichert-Hellert W, Kersting M \& Schoch G (1998) Underreporting of energy intake in 1 to 18 year old German children and adolescents. Z Ernahrungswiss 37, 242-251.

15. Livingstone MB, Robson PJ \& Wallace JM (2004) Issues in dietary intake assessment of children and adolescents. Br J Nutr 92, Suppl. 2, S213-S222.

16. Dufour A, Lafay L \& Volatier JL (2008) La mesure des consommations alimentaires par l'étude INCA2 (The measurement of food consumption by the study INCA2). In Méthodes de sondage, pp. 132-137 [P Guilbert, D Haziza, A Ruiz-Gazen and Y Tillé, editors]. Paris: Dunod.

17. Lioret S, Dubuisson C, Dufour A, et al. (2010) Trends in food intake in French children from 1999 to 2007: results from the INCA (étude Individuelle Nationale des Consommations Alimentaires) dietary surveys. Br J Nutr 103, 585-601.

18. Dubuisson C, Lioret S, Touvier M, et al. (2010) Trends in food and nutritional intakes of French adults from 1999 to 2007: results from the INCA surveys. Br J Nutr $\mathbf{1 0 3}$ 1035-1048.

19. Hercberg S, Deheeger M \& Preziosi P (1994) SU-VI-MAX. Portions alimentaires. Manuel photos pour l'estimation des quantités (Food Portions. Photo Manual for Quantity Estimation). Paris: Poly Technica.

20. Favier JC, Ireland J, Toque C, et al. (1995) Répertoire général des aliments (General Directory of Food). Paris: Tec \& Doc.

21. Ireland J, du Chaffaut L \& Oseredczuk M, et al. (2010) French Food Composition Table, version 2008.1 http://www.afssa. fr. French Food Safety Agency, AFSSA (accessed June 2010)

22. Black AE, Bingham SA, Johansson G, et al. (1997) Validation of dietary intakes of protein and energy against 24 hour urinary $\mathrm{N}$ and DLW energy expenditure in middle-aged women, retired men and post-obese subjects: comparisons with validation against presumed energy requirements. Eur J Clin Nutr 51, 405-413.

23. FAO/WHO/UNU (1985) Energy and Protein Requirements. In Report of a Joint FAO/WHO/UNU Expert Consultation. 
World Health Organ Tech Rep Ser, pp. 1-206. Geneva: FAO/ $\mathrm{WHO} / \mathrm{UNU}$.

24. Schofield WN (1985) Predicting basal metabolic rate, new standards and review of previous work. Hum Nutr Clin Nutr 39, Suppl. 1, S5-S41.

25. Dietz WH, Bandini LG \& Schoeller DA (1991) Estimates of metabolic rate in obese and non obese adolescents. J Pediatr 118, 146-149.

26. Cole TJ, Bellizzi MC, Flegal KM, et al. (2000) Establishing a standard definition for child overweight and obesity worldwide: international survey. $\mathrm{Br}$ Med J 320, 1240-1243.

27. Volatier JL (2000) Enquête INCA individuelle et nationale sur les consommations alimentaires (INCA Individual and National French Dietary Survey). Paris: Tec\&Doc.

28. Lioret S, Touvier M, Lafay L, et al. (2008) Are eating occasions and their energy content related to child overweight and socioeconomic status? Obesity (Silver Spring) 16, 2518-2523.

29. Bandini LG, Must A, Cyr H, et al. (2003) Longitudinal changes in the accuracy of reported energy intake in girls 10-15y of age. Am J Clin Nutr 78, 480-484.

30. Rennie KL, Jebb SA, Wright A, et al. (2005) Secular trends in under-reporting in young people. BrJ Nutr 93, 241-247.

31. McCrory MA, Hajduk CL \& Roberts SB (2002) Procedures for screening out inaccurate reports of dietary energy intake. Public Health Nutr 5, 873-882.

32. Dietary Survey Unit - Nutritional Epidemiology (OCA-EN) (2009) Report of the French INCA2 Dietary Survey (étude Individuelle Nationale des Consommations Alimentaires 2) 2006/2007. Maisons-Alfort: Afssa.

33. Moreno LA, Kersting M, De Henauw S, et al. (2005) How to measure dietary intake and food habits in adolescence: the European perspective. Int J Obes 29, Suppl. 2, S66-S77.

34. EFSA (2009) General Principles for the Collection of National Food Consumption Data in the View of a Pan-European Dietary Survey, vol. 7, Parma: European Food Satefy Authority (EFSA) pp. 1435.

35. Biro G, Hulshof KF, Ovesen L, et al. (2002) Selection of methodology to assess food intake. Eur J Clin Nutr 56, Suppl. 2, S25-S32.
36. EFCOVAL (2010) European Food Consumption Validation (EFCOVAL) Closing Conference, 9-10 September 2009, Utrecht, The Netherlands. General information. Arch Public Health 68, Suppl. 1, S1-S49.

37. Huang TT, Roberts SB, Howarth NC, et al. (2005) Effect of screening out implausible energy intake reports on relationships between diet and BMI. Obes Res 13, 1205-1217.

38. Lioret S, Maire B, Volatier JL, et al. (2007) Child overweight in France and its relationship with physical activity, sedentary behaviour and socio-economic status. Eur J Clin Nutr 61, 509-516.

39. Singh R, Martin BR, Hickey Y, et al. (2009) Comparison of self-reported, measured, metabolizable energy intake with total energy expenditure in overweight teens. Am J Clin Nutr 89, 1744-1750

40. Bandini LG, Schoeller DA, Cyr HN, et al. (1990) Validity of reported energy intake in obese and nonobese adolescents. Am J Clin Nutr 52, 421-425.

41. Perks SM, Roemmich JN, Sandow-Pajewski M, et al. (2000) Alterations in growth and body composition during puberty. IV. Energy intake estimated by the youth-adolescent foodfrequency questionnaire: validation by the doubly labeled water method. Am J Clin Nutr 72, 1455-1460.

42. Savage JS, Mitchell DC, Smiciklas-Wright H, et al. (2008) Plausible reports of energy intake may predict body mass index in pre-adolescent girls. J Am Diet Assoc 108, 131-135.

43. Fisher JO, Johnson RK, Lindquist C, et al. (2000) Influence of body composition on the accuracy of reported energy intake in children. Obes Res $\mathbf{8}, 597-603$.

44. Ventura AK, Loken E, Mitchell DC, et al. (2006) Understanding reporting bias in the dietary recall data of 11-year-old girls. Obesity (Silver Spring) 14, 1073-1084.

45. Rodriguez G \& Moreno LA (2006) Is dietary intake able to explain differences in body fatness in children and adolescents? Nutr Metab Cardiovasc Dis 16, 294-301.

46. Beaton GH (1994) Approaches to analysis of dietary data: relationship between planned analyses and choice of methodology. Am J Clin Nutr 59, Suppl. 1, S253-S261. 